\title{
A context-specific detrimental effect of UCS preexposure on place conditioning with morphine
}

\author{
SHERRY A. MCKEE, RILEY E. HINSON, and BRUCE W. BAXTER \\ University of Western Ontario, London, Ontario, Canada
}

\begin{abstract}
The effect of morphine preexposure on place conditioning with morphine was investigated. In the first experiment, five injections of $10 \mathrm{mg} / \mathrm{kg}$ morphine were administered to rats prior to place conditioning or taste-aversion training with morphine. Although this number of preexposures retarded taste-aversion learning, there was no effect on place conditioning. In subsequent experiments we investigated the role of context blocking in UCS preexposure in place conditioning. In one experiment, preexposure to five morphine injections prior to place conditioning resulted in a reduced place preference, compared with preexposure and place conditioning in different contexts. However, the overall detrimental effect of morphine preexposure was questionable, because the rats that were preexposed were only marginally different from those that were not preexposed. In a final experiment we examined the effect of a context change from preexposure to place conditioning with 15 preexposures and demonstrated a detrimental effect of preexposure on place conditioning that was context specific. These results support a role of classical conditioning in place-preference conditioning with morphine.
\end{abstract}

Place conditioning is thought to involve classical conditioning (see Wall, Hinson, Schmidt, Johnston, \& Streather, 1990). A drug effect (the UCS: unconditional stimulus) is presented contingently with a set of distinctive environmental cues (the CS: conditional stimuli) on some days, and on other days physiological saline is paired with another set of distinctive environmental cues. After several training sessions, animals receive simultaneous access to both sets of cues, and the amount of time spent in the presence of each set of cues is measured. Approach to or avoidance of drug-related cues is thought to be dependent on, respectively, the rewarding or aversive effects of the drug (Bardo, Miller, \& Neisewander, 1984; Mucha \& Iverson, 1984).

Although place conditioning presumably involves Pavlovian conditioning, little research has been conducted to test the relationship, and important questions concerning the contribution of associative versus nonassociative processes (Scoles \& Siegel, 1986) remain. One strategy for assessing whether associative learning is involved in drugrelated behavioral change is to determine whether wellestablished Pavlovian conditioning operations predictably affect the phenomenon (see Hinson, McKee, Lovenjak, \& Wall, 1993; Siegel, 1983). In the present experiments we adopted this strategy by examining the relation between UCS preexposure and place-preference conditioning with morphine.

This research was supported by a grant from the Natural Sciences and Engineering Research Council of Canada to R.E.H. Reprint requests should be sent to R. E. Hinson, Department of Psychology, University of Western Ontario, London, Ontario, Canada N6A 5C2.
Exposure to the UCS before the initiation of CS-UCS pairings retards the development of excitatory conditioning (for a review, see Randich \& LoLordo, 1979a). Studies examining this UCS preexposure effect and subsequent morphine place conditioning have produced conflicting findings. On the one hand, Shippenberg, EmmettOglesby, Ayesta, and Hertz (1988) demonstrated reduced conditioned place preference in rats following morphine preexposure, suggesting that morphine place-preference conditioning is subject to a UCS preexposure effect and does follow the rules of Pavlovian learning. On the other hand, some investigators have found no effect of morphine preexposure on later place preference (Martin, Bechara, \& van der Kooy, 1988). Moreover, morphine preexposure actually increased later place-preference conditioning with morphine in two other studies (Gaiardi et al., 1991; Lett, 1989).

The purpose of the present experiments was to investigate the effect of UCS preexposure in place conditioning with morphine and to determine whether any UCS preexposure effect was context specific.

\section{EXPERIMENT 1}

The purpose of Experiment 1 was to compare the effect of morphine preexposure in place conditioning and taste-aversion learning with morphine. Previous research has demonstrated that morphine produces a conditioned taste aversion, and that preexposure to morphine attenuates this effect (Cappell \& LeBlanc, 1977). As described previously, the effect of morphine preexposure on place conditioning with morphine is less clear. Consequently, 
we compared the effect of the same number of morphine preexposures in the two procedures.

\section{Method}

\section{Subjects}

The subjects were 64 male Long-Evans rats obtained from Canadian Breeding Farms, St. Constant, Quebec. The rats were experimentally naive and weighed between 250 and $300 \mathrm{~g}$ at the start of the experiment. They were housed individually with free access to food and were acclimated to a 23.5-h water-deprivation schedule 1 week prior to the start of the experiment. The rats were maintained on a 12:12-h light:dark cycle, with an illumination period from 0700 to $1900 \mathrm{~h}$. Experimental sessions commenced between 0900 and $1000 \mathrm{~h}$.

\begin{abstract}
Apparatus
Place conditioning occurred in wooden, three-compartment straight-alley boxes covered with hinged, clear Plexiglas lids. The three compartments were separated by guillotine doors. The dimensions of the boxes were $72 \times 28 \times 25 \mathrm{~cm}$. Each of the two end compartments measured $28 \times 28 \times 25 \mathrm{~cm}$; the center compartment measured $16 \times 28 \times 25 \mathrm{~cm}$. One end compartment was white and had hardwood chips covering the floor, and the other end compartment was black and had no floor covering. The plywood in the center compartment was unpainted. Place-conditioning boxes and home cages were located in different rooms.

Graduated drinking tubes containing a $0.15 \%(w / v)$ saccharin solution were attached to the front center of each home cage during taste-aversion conditioning. For the two-bottle tests, saccharin and water solutions were randomly placed to the right and left of the tube position that was used during taste-aversion training.
\end{abstract}

\section{Procedure}

There were two phases in the experiment. The first phase was UCS preexposure, and the second phase involved either place conditioning or taste-aversion training, depending on group designation.

Phase 1: Preexposure. The subjects were randomly assigned to one of two preexposure conditions of 32 rats each. In one condition $(\mathrm{Px})$, the rats received drug preexposure in their home cages in a 10-day procedure. We administered $10 \mathrm{mg} / \mathrm{kg}$ morphine i.p. (intraperitoneally) to each rat on even-numbered days and equivolume saline vehicle $(1 \mathrm{ml} / \mathrm{kg}$ ) on odd-numbered days. The rats in the no-preexposure condition (NPx) received a saline injection on each of the pretreatment days.

At the completion of this phase, a random half of the subjects from each preexposure condition $(n=16)$ received taste-aversion training, and the other half received place conditioning. These groups were further randomly subdivided to receive either morphine (M) or saline (S) during training. Therefore, for both taste aversion and place conditioning, four groups of 8 rats each were formed: preexposed to morphine and trained with morphine (Px-M), not preexposed to morphine and morphine trained (NPx-M), preexposed to morphine and trained with saline (Px-S), and not preexposed to morphine and saline trained (NPx-S).

Phase 2A: Taste aversion. Training occurred over four 5-day blocks in the animal colony room. Groups Px-M and NPx-M received a $10-\mathrm{mg} / \mathrm{kg}$ i.p. morphine injection in their home cages on Days 1 and 3 of each 5-day block. Saline vehicle was administered on Days 2 and 4. One hour later, they received 30-min access to a saccharin solution on morphine days and 30-min access to water on saline days. Groups Px-S and NPx-S received saline treatment on each day. One hour later, these rats received 30 -min access to either water or saccharin, which alternated from day to day. The amount of saccharin consumed was recorded for all the subjects. Day 5 of each training block consisted of a two-bottle test: All the groups were injected with saline $1 \mathrm{~h}$ prior to the simulta- neous presentation of saccharin and water solutions for a period of $30 \mathrm{~min}$.

Phase 2B: Place conditioning. Training occurred over four 5-day blocks. Groups Px-M and NPx-M received a $10-\mathrm{mg} / \mathrm{kg}$ i.p. morphine injection in their home cages on Days 1 and 3 of each 5-day block; saline vehicle was administered on Days 2 and 4 . We transported the rats to the conditioning apparatus $1 \mathrm{~h}$ later. The rats were confined to the white compartment of the apparatus for $30 \mathrm{~min}$ on morphine days and to the black compartment for $30 \mathrm{~min}$ on saline days. Groups Px-S and NPx-S received saline treatment on each day. One hour later, these rats were confined for $30 \mathrm{~min}$ to one of the end boxes, which alternated from day to day. Day 5 of each training block consisted of a choice test: All the groups received a home-cage saline injection $1 \mathrm{~h}$ prior to a 30 -min period of access to all three compartments of the conditioning box.

\section{Results}

\section{Taste Aversion}

Figure 1 presents the mean amount of saccharin consumed during the eight saccharin presentations during taste-aversion training. The rats that were not preexposed and received morphine training consumed less saccharin than did those in any of the other groups. A mixed-design analysis of variance (ANOVA; preexposure drug $\times$ training drug $\times$ training trial) yielded significant preexposure drug $\times$ training trial $[F(7,196)=2.49, p<.05]$ and training drug $\times$ training trial $[F(7,196)=6.53, p<.05]$ interactions. Separate $2 \times 2$ factorial ANOVAs of each conditioning trial revealed a main effect of training drug on Conditioning Trial $1[F(1,28)=16.73, p<.005]$ and an interaction between preexposure drug and training drug on each of Trials 3-8 $[F \mathrm{~s}(1,28)>6.05, p \mathrm{~s}<$ $.02]$. Newman-Keuls comparisons $(\alpha=.05)$ revealed that Group NPx-M drank significantly less saccharin on Trials 3-8 than did all the other groups, which did not differ from one another.

Figure 2 presents the saccharin preference ratios for the four two-bottle tests. The ratio is the amount of saccharin consumed (the CS for morphine-trained groups) divided by the total amount of both solutions consumed. The rats that were not preexposed and received morphine training consumed less saccharin than did all the other groups. A mixed-design ANOVA (preexposure drug $\times$ training drug $\times$ test trial) yielded a significant preexposure drug $X$ training drug interaction $[F(1,28)=11.37, p<.002]$. Because there was no significant effect of trial, the data were collapsed across trials and a simple main effects analysis was conducted on the ratio scores averaged over all trials. The averaged ratios (SEM) for Groups Px-M, NPx-M, Px-S, and NPx-S were, respectively, .838 (.0178), .534 (.0534), .849 (.0263), and .774 (.0269). The analysis indicated that Group NPx-M consumed significantly less saccharin than did all the other groups, which did not differ.

\section{Place Conditioning}

Figure 3 presents ratios for time spent in the white compartment for the four choice tests in place conditioning. The ratio is the amount of time spent in the white com- 


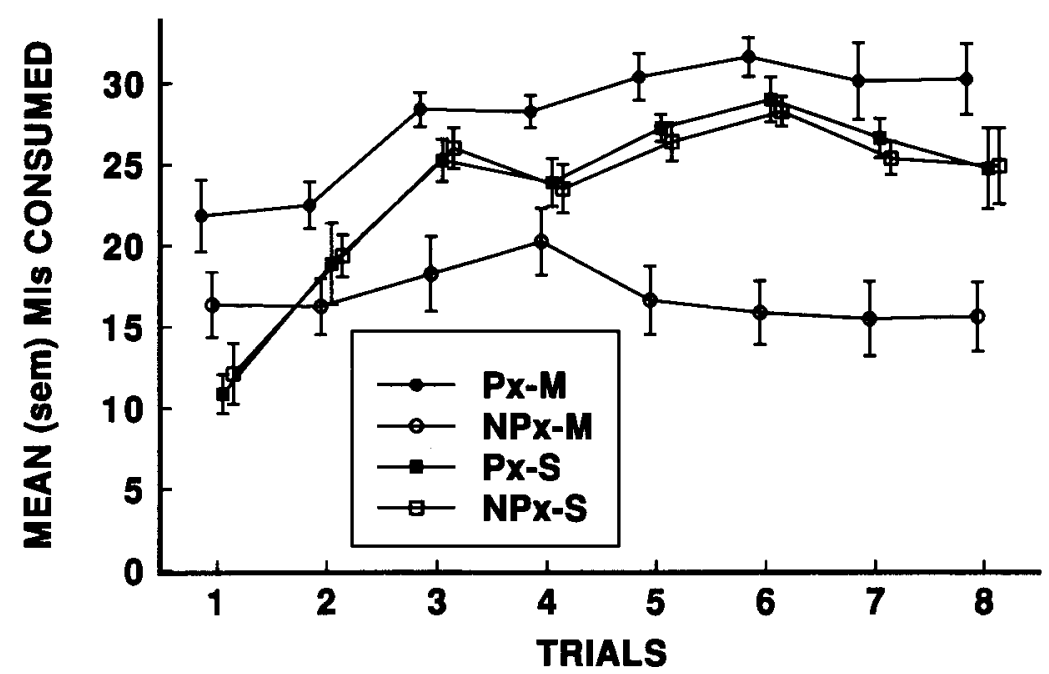

Figure 1. Mean (SEM) milliliters of saccharin consumed during the conditioning trials for the subjects that received taste-aversion training in Experiment 1 . In the first phase of the experiment, the subjects received either five morphine preexposures (Px) or no drug preexposure (NPx). During the second phase, they received taste-aversion training with either saccharin paired with morphine $(\mathbf{M})$ or saccharin paired with saline (S).

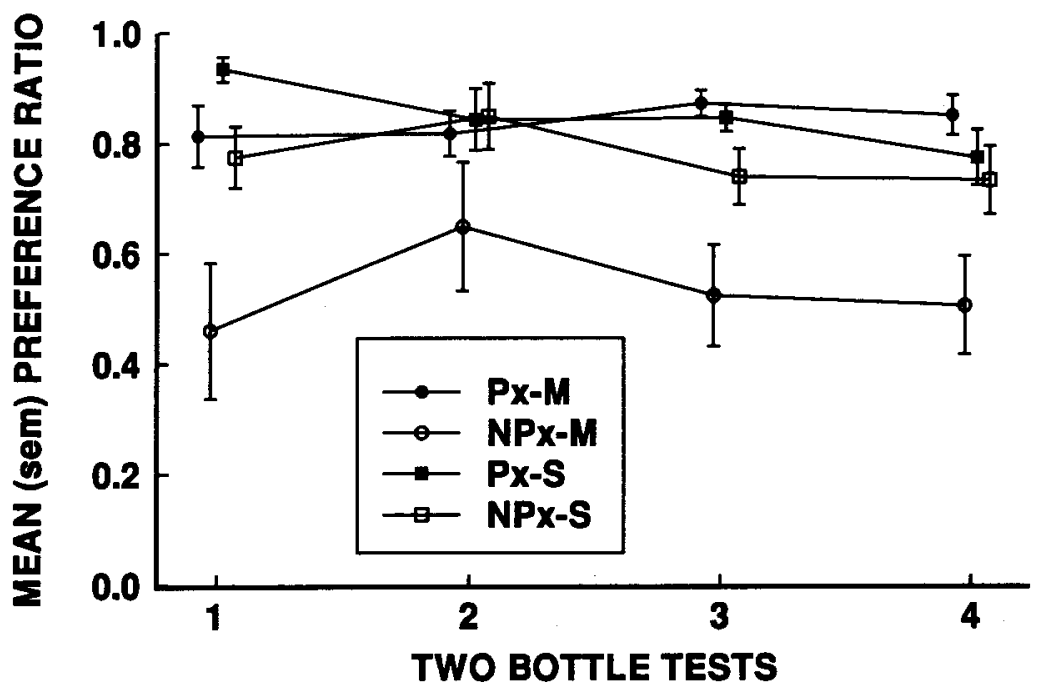

Figure 2. Mean (SEM) preference ratios for saccharin (saccharin consumption/saccharin + water consumption) during the two-bottle tests given during Day 5 of each 5-day training block in Experiment 1. In the first phase of the experiment, the subjects received either five morphine preexposures (Px) or no drug preexposure (NPx). During the second phase, they received taste-aversion training with either saccharin paired with morphine $(M)$ or saccharin paired with saline (S).

partment (the CS for morphine-trained groups) divided by the total amount of time spent in the white and black compartments. The rats that were morphine trained spent more time in the white compartment than did those that were saline trained, irrespective of preexposure experience. A mixed-design ANOVA (preexposure drug $\times$ training drug $\times$ test trial) yielded a significant training drug $\times$ test trial interaction $[F(3,84)=8.58, p<.0005]$. No effect of preexposure was statistically significant; there- fore, the data for each choice test were collapsed across this factor. Comparisons of drug- versus saline-trained subjects revealed a significant effect of drug for each of the four choice tests $[F \mathrm{~s}(1,30)>7.32, p s<.01]$.

\section{Discussion}

For taste-aversion training in the present study, a morphine injection (UCS) preceded the saccharin presenta- 


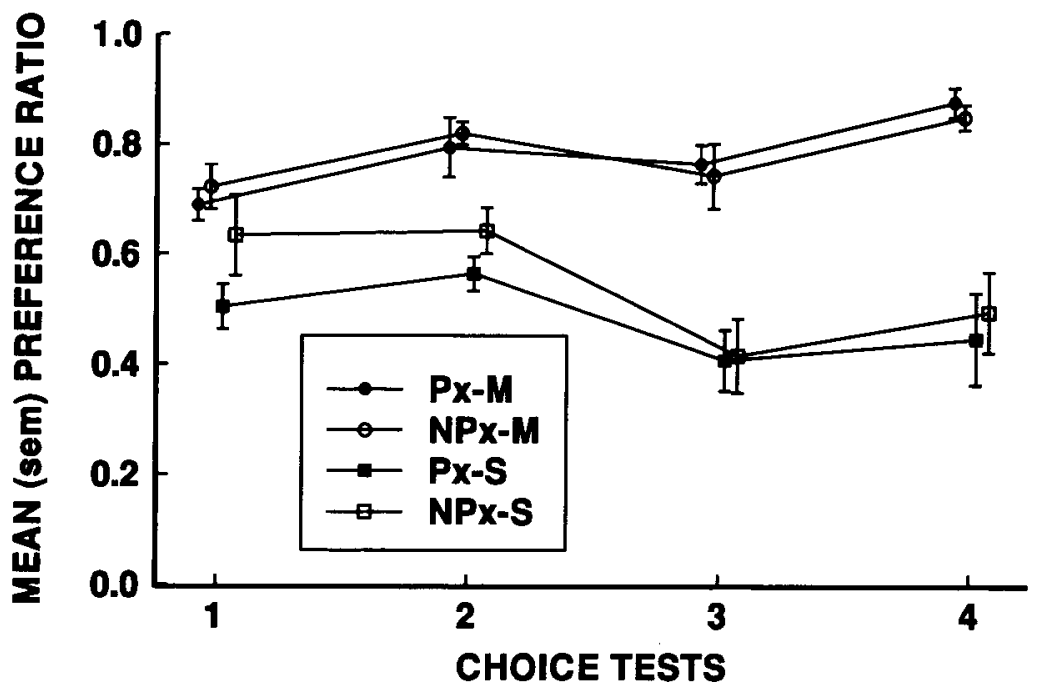

Figure 3. Mean (SEM) preference ratios for the white compartment (time spent in white compartment/time spent in white compartment + time spent in black compartment) during the choice tests given during Day 5 of each 5-day training block in Experiment 1 . In the first phase of the experiment, the subjects received either five morphine preexposures (Px) or no drug preexposure (NPx). During the second phase, they received place conditioning with either morphine $(M)$ or saline (S).

tion (CS) by $1 \mathrm{~h}$ because this temporal arrangement was found to produce the greatest conditioned place preference in a parametric study of CS-UCS intervals (Hinson et al., 1993). Sherman, Pickman, Rice, Liebeskind, and Holman (1980) gave morphine injections immediately before the presentation of the flavored solution and found no evidence of a conditioned taste avoidance. However, in the present study, a taste avoidance was demonstrated when the drug injection was given $1 \mathrm{~h}$ prior to the CS presentation. Because the preference ratios for Group NPX-M during the two-bottle tests were generally greater than .50 , it may be inappropriate to call this a taste aversion; instead, Group NPx-M simply may not have developed the preference for saccharin solution that was seen in the other groups.

Preexposure to morphine did not attenuate the conditioned place preference produced by morphine. Thus, even though five UCS preexposures were sufficient to attenuate a taste avoidance, identical UCS preexposure did not alter the acquisition of a conditioned place preference. One explanation is that prior exposure to the UCS has no effect on the development of a conditioned place preference. Alternatively, it simply may be that more UCS preexposures are needed to affect place conditioning than are needed to affect taste-avoidance learning.

An additional consideration in trying to explain the lack of an effect of UCS preexposure on place preference involves the role of context conditioning (see Randich $\&$ LoLordo, 1979b). One interpretation of the UCS preexposure effect is based on the idea of blocking the conditioning to the nominal CS by contextual stimuli. During a period of UCS preexposure, contextual stimuli should become conditioned. If these contextual cues are then present during subsequent conditioning to a discrete CS, they may block any association between the nominal CS and the UCS.

One way to test this context-blocking hypothesis of the UCS preexposure effect is to vary the contextual similarity between preexposure and conditioning with the nominal CS (see Hinson, 1982). Conditioning to the nominal CS should be attenuated only if the context between preexposure and conditioning remains the same.

The context-blocking hypothesis may account for the results found in the present experiment. A preexposure effect was demonstrated in taste avoidance when both preexposure and subsequent taste-avoidance training occurred in the same context (i.e., the colony room). In place conditioning, a preexposure effect was not demonstratedan outcome that may have been due to the fact that preexposure and place-conditioning training occurred in different contexts (preexposure in the colony room and place conditioning in the experimental laboratory). In this regard, Martin et al. (1988) preexposed subjects to the UCS in their home cages and later conducted place conditioning in a different context; no preexposure effect was demonstrated.

The following experiments were designed to investigate whether a UCS preexposure effect does occur during place conditioning and whether any such effect is context specific.

\section{EXPERIMENT 2}

To test the context-blocking hypothesis of UCS preexposure in place conditioning, it was necessary to identify contextual stimuli that could be associated with mor- 
phine during preexposure and then compounded with the nominal CS (visual cues) in the place-conditioning boxes during conditioning. In Experiment 2, rats were administered the schedule of preexposure that was used in Experiment 1; however, preexposure injections were paired with one of two distinct tactile cues (sawdust or gravel) outside of the place-conditioning apparatus. The rats were then given a choice test between the tactile cues in the place-conditioning boxes to determine whether an association had been formed to the tactile cues and whether it would transfer to the place-conditioning boxes.

\section{Method}

\section{Subjects}

The subjects were 24 male Long-Evans rats. All other details regarding the subjects were identical to those of Experiment 1, except that all the rats had free access to water.

\section{Apparatus}

Preexposure occurred in wooden, five-compartment (each compartment was $14.5 \times 28 \times 25 \mathrm{~cm}$ ) straight-alley boxes with hinged, clear Plexiglas lids. The boxes were unpainted plywood with either sawdust or gravel covering the floor. The preexposure boxes were located in the same room as the place-conditioning boxes. Choice tests occurred in the place-conditioning boxes described in Experiment 1.

\section{Procedure}

Training occurred over a 10-day period. The subjects were randomly assigned to either morphine $(M ; n=16)$ or saline $(S ; n=$ 8) training. Half of the morphine-trained rats were administered a $10-\mathrm{mg} / \mathrm{kg}$ i.p. injection of morphine paired with sawdust (SW/M) on odd-numbered days; on even days, a saline injection was paired with gravel. The other morphine rats (GR/M) had morphine injections paired with gravel and saline injections paired with sawdust. The rats in the saline condition received only saline injections, with alternating exposure to the tactile cues (SW/S and GR/S). The rats were injected in the animal colony room $1 \mathrm{~h}$ before transportation to the laboratory and confinement to the preexposure boxes for $30 \mathrm{~min}$.

We administered a choice test on Day 11 . For each subject, the tactile cue previously associated with morphine (or designated as the dependent-measure cue for the saline-only animals) was placed in one end compartment, and the alternative tactile cue was placed in the other end compartment. Both end compartments were painted white, because the purpose of this test was to assess approach to and avoidance of tactile cues only. The rats received an injection of saline $1 \mathrm{~h}$ prior to a 30 -min period of access to all three compartments.

\section{Results}

Figure 4 shows the mean preference ratios for the dependent-measure side during the choice test. The rats trained with morphine had significantly higher preference ratios than the saline controls. A factorial ANOVA (training drug $\times$ tactile cue) yielded a main effect of training drug $[F(1,20)=7.213, p<.05]$, thus indicating a significant place preference.

\section{Discussion}

Five pairings of either tactile cue with morphine (which paralleled the number of preexposures given in Experi-

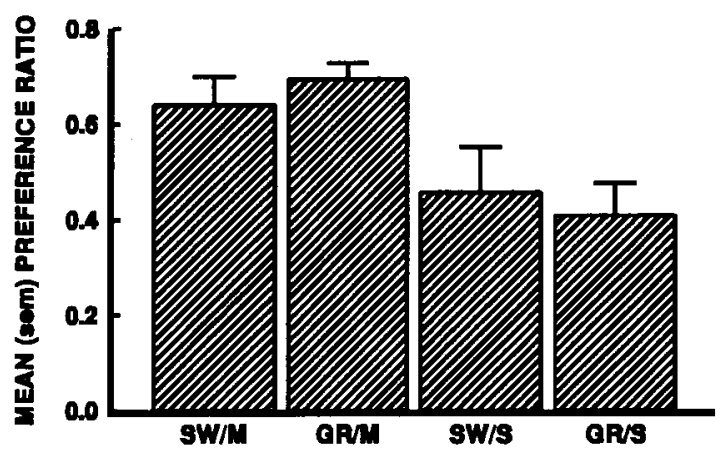

Figure 4. Mean (SEM) preference ratios for the tactile cue paired with morphine (or the designated dependent-measure tactile cue for the animals preexposed to only saline) during the single choice test given at the end of Experiment 2. The subjects had either sawdust (SW) or gravel (GR) as their designated cue, and this was paired with five injections of either morphine (M) or saline (S).

ment 1) were sufficient to produce a place preference for the tactile cues. The association that was formed between the tactile cues and morphine in the preexposure boxes transferred to the place-conditioning environment.

There was a difference in the preference ratios of the morphine-trained rats between Experiments 1 and $2(.8$ vs. .6). The subjects were water deprived in Experiment 1, but not in Experiment 2. Water deprivation was used in Experiment 1 so that the subjects receiving placeconditioning training would be treated similarly to those receiving taste-avoidance training. Additionally, the cues of the end boxes were different in the two experiments. These factors may have contributed to the difference in preference ratios across experiments.

\section{EXPERIMENT 3}

To test the role of context blocking in place conditioning, some rats received place conditioning in the same context that was used for UCS preexposure, and the other subjects received place conditioning in a context that was different from that used for preexposure. The amount of conditioning to the nominal CS (white vs. black cues) was then assessed during choice tests.

\section{Method}

\section{Subjects and Apparatus}

The subjects were 48 male Long-Evans rats. Place-conditioning boxes were identical to those described in Experiment 1. All other details regarding subjects, apparatus, and drugs were identical to those of Experiment 2.

\section{Procedure}

There were two phases in the present experiment: UCS preexposure and place conditioning.

Phase 1: Preexposure. This phase occurred over 10 days. Randomly assigned rats received either morphine preexposure $(n=$ 32 ) or no drug preexposure $(n=16)$. The morphine-preexposed subjects were subassigned to one of two conditions: half of the rats received morphine paired with sawdust on even-numbered days and 
saline paired with gravel on odd-numbered days, and the remaining rats received the reverse cue-substance pairings. The rats in the no-drug preexposure condition received 10 saline injections with alternating exposure to the tactile cues. Thus, three groups were formed: morphine preexposed in sawdust $(\mathrm{Px} / \mathrm{SW})$, morphine preexposed in gravel (Px/GR), and no drug preexposure (NPx). Injections occurred in the animal colony room $1 \mathrm{~h}$ prior to transportation to the laboratory and placement in the preexposure boxes for $30 \mathrm{~min}$.

At the completion of this phase, the rats from each preexposure condition were randomly assigned to one of two conditions and received place-conditioning training with either morphine or saline. During place conditioning, all drug injections were paired with the white compartment and sawdust. The subjects receiving drug preexposure in sawdust were designated as being place conditioned in the same context (Same) because sawdust was present for both preexposure and place conditioning. Those that were drug preexposed in gravel were designated as receiving place conditioning in a different context (Diff) because the context changed from preexposure to place conditioning. Thus, six groups ( $n=8$ each) were formed: morphine preexposed and morphine place conditioned in the same context (Px/M/Same), morphine preexposed and saline place conditioned in the same context (Px/S/Same), morphine preexposed and morphine place conditioned in a different context (Px/M/Diff), morphine preexposed and saline place conditioned in a different context (Px/S/Diff), not preexposed and morphine place conditioned $(\mathrm{NPx} / \mathrm{M})$, and not preexposed and saline place conditioned (NPx/S). Because the subjects in the latter two groups were not drug preexposed, there was no context designation.

Phase 2: Place conditioning. Training occurred over three 5-day blocks. Details of place conditioning were identical to those of Experiment 1 . There was no floor covering in any compartment during choice testing. Thus, the choice test assessed the preference behavior of rats for the white versus black cues only.

\section{Results}

Figure 5 presents the mean preference ratios for the white side for the three choice tests. The rats that were preexposed and conditioned with morphine in the same context had lower preference ratios than did the rats preexposed and conditioned with morphine in different contexts. A mixed-design ANOVA (groups $\times$ test trial) yielded a significant effect of groups $[F(5,42)=5.01$, $p<.001]$. None of the effects of trial were statistically significant; therefore, the data were averaged across choice tests. The averaged ratios (SEM) for Groups NPx/S, Px/S/Diff, Px/S/Same, Px/M/Same, NPx/M, and $\mathrm{Px} / \mathrm{M} / \mathrm{Diff}$ were, respectively, .392 (.031), .410 (.061), $.456(.040), .505(.072), .618(.039)$, and $.651(.033)$. Four planned comparisons were conducted. A comparison of Group NPx/M with Group NPx/S indicated that morphine induced a preference $[t(42)=3.32, p<.001]$. Groups Px/M/Same and Px/M/Diff were compared separately with Group NPx/M to determine whether there was a preexposure effect. The difference between Groups $\mathrm{Px} / \mathrm{M} /$ Same and $\mathrm{NPx} / \mathrm{M}$ did not attain a conventional level of statistical significance $[t(42)=1.655, p=.051]$. There was no difference between Groups Px/M/Diff and $\mathrm{NPx} / \mathrm{M}$, as expected. Finally, Group Px/M/Same had significantly lower ratios than did Group Px/M/Diff $[t(42)=$ $2.14, p<.025$ ]. All other pairwise differences were assessed with the Newman-Keuls test $(\alpha=.05)$. Group $\mathrm{NPx} / \mathrm{M}$ had significantly higher ratios than did Groups $\mathrm{Px} / \mathrm{S} / \mathrm{Same}$ and Px/S/Diff; Group Px/M/Diff differed sig-

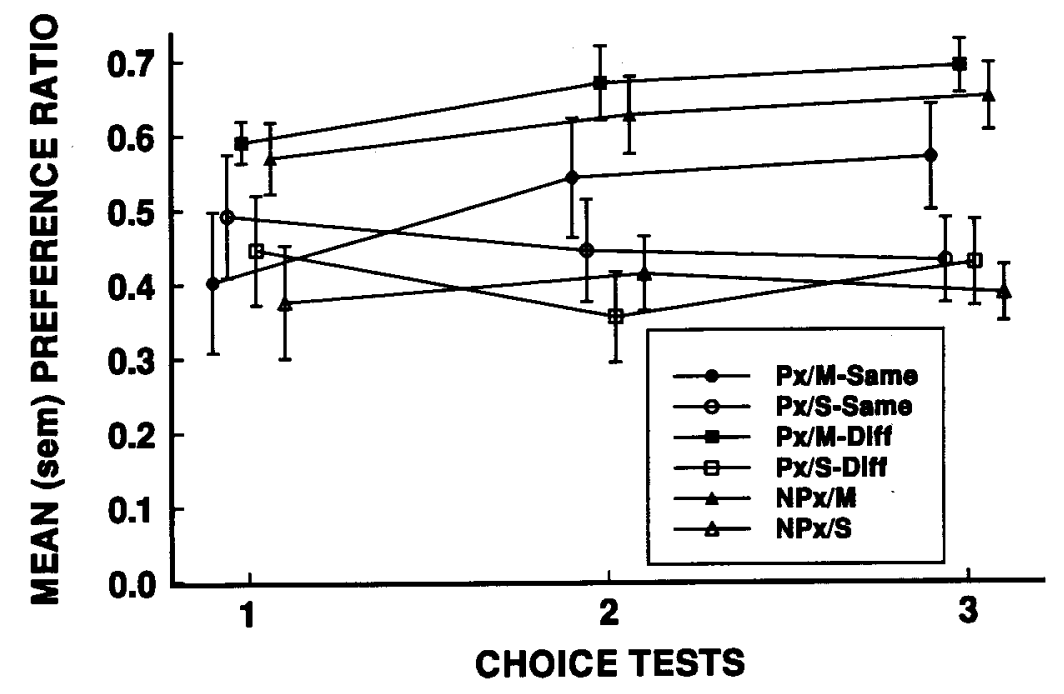

Figure 5. Mean (SEM) preference ratios for the white compartment (time spent in white side/time spent in white side + time spent in black side) for the choice tests given during Day 5 of each 5-day training block for Experiment 3. During the first phase, the subjects received either five morphine preexposures (Px) or no drug preexposure (NPx). During the second phase, they received place conditioning with either morphine $(M)$ or saline (S). Place conditioning was either in the same context as preexposure (Same) or in a context different from preexposure (Diff). 
nificantly from each of the groups that had received only saline during place conditioning $(\mathrm{NPx} / \mathrm{S}, \mathrm{Px} / \mathrm{S} / \mathrm{Same}$, and $\mathrm{Px} / \mathrm{S} / \mathrm{Diff}$ ). No other differences were significant.

\section{Discussion}

The results of Experiment 3 provide some evidence of a context-specific UCS preexposure effect in place conditioning. The rats that received place conditioning with a color cue and a tactile cue paired with morphine, following preexposure to morphine in the presence of that tactile cue (Group $\mathrm{Px} / \mathrm{M} / \mathrm{Same}$ ), demonstrated less of a preference for the color than did those that received place conditioning with the color cue and a tactile cue that had been associated with saline during preexposure (Group $\mathrm{Px} / \mathrm{M} / \mathrm{Diff}$ ). Additionally, preexposure to morphine did not affect place conditioning when conditioning took place in the presence of a tactile cue associated with saline preexposure (Group Px/M/Diff compared with $\mathrm{NPx} / \mathrm{M}$ ). However, direct evidence for a deleterious effect of morphine preexposure on subsequent place conditioning was not as strong as expected, because the preference behavior of Group Px/M/Same was only marginally lower than that of Group NPx/M.

\section{EXPERIMENT 4}

The marginal effect of UCS preexposure in the previous experiment may be related to the number of UCS pre- exposures. According to the context-blocking hypothesis, the extent to which UCS preexposure retards subsequent conditioning to the nominal CS is dependent on the amount of conditioning to the preexposure context and the relative salience of the preexposure context and nominal CS during compound conditioning. Conditioning to the tactile cues during preexposure would not prevent conditioning to the added visual cue during compound place conditioning unless conditioning to the tactile cue during preexposure was asymptotic. Thus, the finding that Group $\mathrm{Px} / \mathrm{M} /$ Same was only marginally different from Group $\mathrm{NPx} / \mathrm{M}$ may have been due to the number of morphine preexposures. To test this possibility, the same general design of the previous experiment was used, with the exception that the number of UCS preexposures was increased from 5 to 15 .

\section{Method}

Subjects, Apparatus, and Procedure

The subjects were 48 male Long-Evans rats. All other details regarding subjects, apparatus, drugs, procedures, and group assignment were identical to those of Experiment 3. We administered a total of 15 morphine injections over 30 days.

\section{Results}

Figure 6 presents the mean preference ratios for the white side of the compartment for the three choice tests. The rats preexposed and place conditioned with morphine

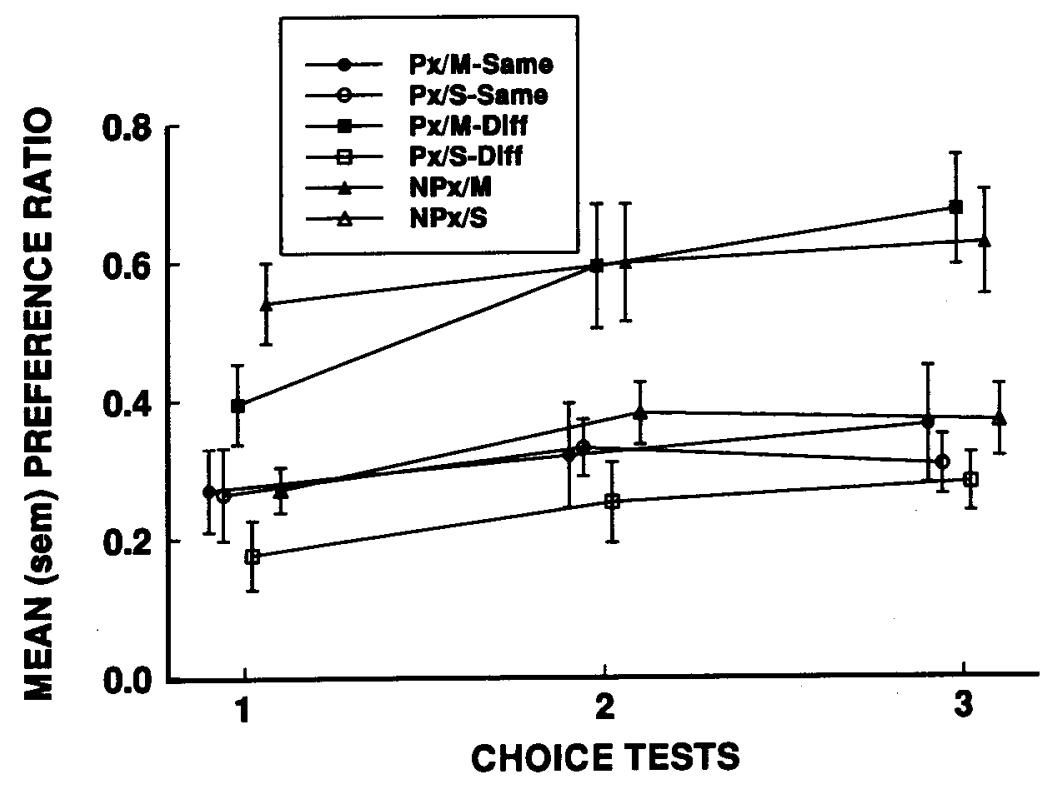

Figure 6. Mean (SEM) preference ratios for the white compartment (time spent in white side/time spent in white side + time spent in black side) for the choice tests given during Day 5 of each 5-day training block for Experiment 4 . During the first phase, the subjects received either 15 morphine preexposures (Px) or no drug preexposure (NPx). During the second phase, they received place conditioning with either morphine (M) or saline (S). Place conditioning was either in the same context as preexposure (Same) or in a context different from preexposure (Diff). 
in the same context had lower preference ratios than either the rats preexposed and conditioned in different contexts or those that received no preexposure.

A mixed-design ANOVA (group $\times$ test trial) yielded a significant effect of group $[F(5,42)=7.25, p<.05]$ and trial $[F(2,84)=13.44, p<.05]$. The averaged ratios $(S E M)$ across all choice tests were $.589(.09), .559$ (.09), .340 (.04), .318 (.05), .300 (.08), and .236 (.06), respectively, for Groups NPx/M, Px/M/Diff, NPx/S, $\mathrm{Px} / \mathrm{M} / \mathrm{Same}$, Px/S/Same, and Px/S/Diff. Four planned comparisons were conducted on these collapsed group averages. Group $\mathrm{NPx} / \mathrm{M}$ had significantly higher ratios than did Group NPx/S $[t(42)=4.26, p<.0005]$. Group $\mathrm{Px} / \mathrm{M} / \mathrm{Same}$ had significantly lower ratios than did Group $\mathrm{NPx} / \mathrm{M}[t(42)=4.63, p<.0005]$, but Group Px/M/Diff did not differ significantly from Group NPx/M. Finally, Group Px/M/Diff had significantly higher ratios than did Group Px/M/Same $[t(42)=4.12, p<.0005]$. All other pairwise comparisons were conducted with the NewmanKeuls test $(\alpha=.05)$. Group Px/M/Diff had higher ratios than did the groups receiving place conditioning with saline (Px/S/Diff, Px/S/Same, and NPx/S). Group NPx/M was significantly different from Groups Px/S/Diff and $\mathrm{Px} / \mathrm{S} /$ Same.

\section{Discussion}

There was a deleterious effect of morphine preexposure on subsequent place-preference conditioning, but only if the preexposure context was present during place conditioning. This finding provides clear evidence of a context-specific UCS preexposure effect in place conditioning with morphine that is analogous to the contextspecific UCS preexposure effect found in a variety of traditional classical conditioning preparations (see Randich \& LoLordo, 1979a). In general, the preference ratios of all the groups were lower during the first choice test of Experiment 4 than those during the first choice test of Experiment 3. However, by the third choice test, the two groups that were expected to show a preferenceGroups NPx/M and Px/M/Diff-had preference ratios of .68 and .63 , respectively, which are similar to those of the same two groups in Experiment 3. Thus, it is clear that a place preference developed in this experiment, and that the development of that preference was prevented by the presence of tactile cues paired with morphine during preexposure.

\section{GENERAL DISCUSSION}

The finding of a context-specific detrimental effect of UCS preexposure provides support for the view that the preference behavior seen in place conditioning with morphine results from Pavlovian conditioning (see Hinson et al., 1993). Shippenberg et al. (1988) have also reported a deleterious effect of morphine preexposure on placepreference conditioning. However, Shippenberg et al. reported that the deleterious effect of morphine preexpo- sure was not context specific, in contrast to the findings of the present study. There were several procedural differences between the present study and that of Shippenberg et al. One difference that might be particularly relevant is that between the parameters of preexposure in the two studies. In our study, we gave one drug injection every other day with a distinct set of tactile cues and, on alternate days, a saline injection with a different set of tactile cues. This procedure was explicitly designed to lead to conditioning to the preexposure tactile cues paired with the drug, because we envisioned the UCS preexposure procedure as being akin to a blocking procedure. In contrast, Shippenberg et al. gave a drug injection every $12 \mathrm{~h}$ over the course of 4 days. Their procedure would be less likely to lead to conditioning to contextual cues because there was probably some degree of drug effect continuously present, and the preexposure context was not explicitly distinguished by giving saline injections in another context. There is evidence that their preexposure procedure did not lead to conditioning to the preexposure context, because the deleterious effect of preexposure was eliminated if 1 week intervened between preexposure and place conditioning. Such a "rest" period should not have eliminated an effect based on conditioning, because extinction is generally required to substantially reduce conditioned effects. Thus, the deleterious effect of UCS preexposure reported by Shippenberg et al. may have been due to nonassociative factors, whereas the effects seen in the present study were due to associative factors.

Gaiardi et al. (1991) and Lett (1989) have reported that morphine preexposure produced preference conditioning in a procedure that otherwise was ineffective. That is, animals preexposed to morphine developed a place preference, whereas animals that were not preexposed did not. The fact that nonpreexposed animals that were subsequently conditioned with morphine did not develop a place preference makes comparisons with the present experiments difficult. In the present experiments, a procedure that led to the development of a place preference in nonpreexposed animals (i.e., Group NPx/M) was used. When preexposure was given prior to the use of an effective place-conditioning procedure, there was a deleterious effect of such preexposure. Perhaps preexposure has a different effect if the place-conditioning procedure that is used is not itself sufficient to produce a preference.

The mechanism of the deleterious effect of UCS preexposure remains unclear. However, it is clear that the effect can be context specific. One explanation is that prior learning to the tactile cues of the preexposure context prevented conditioning to the nominal CS by rendering the UCS unsurprising, or expected. This is a generally accepted explanation for the phenomenon of blocking (see Kamin, 1961), and it may be applied to the contextspecific UCS preexposure effect (see Hinson, 1982). Another factor may involve context-specific tolerance. The development of a conditioned place preference supposedly depends on some reinforcing effect of morphine's being paired with the place-conditioning CS (Shippenberg 
et al., 1988). Tolerance to the reinforcing effect of morphine may develop (Shippenberg et al., 1988); it is also known that tolerance to most drug effects is context specific (see Siegel, 1983). During preexposure, tolerance to the reinforcing effect of morphine may develop, but such tolerance may be context specific. When place conditioning subsequently occurs in the same context as preexposure, context-specific tolerance would reduce the reinforcing effect of morphine, leading to reduced preference conditioning. However, if subsequent place conditioning took place in a context different from the preexposure context, then there should be little or no tolerance to morphine's reinforcing effect and, consequently, no attenuation of preference conditioning. A test of the context specificity of analgesic tolerance was given at the end of Experiment 2 of the present study. It was found that tolerance to the analgesic effect of morphine had developed during the preexposure phase, and that it was context specific. Although the relationship between tolerance to morphine's analgesic and reinforcing effects is not clear (see Hinson et al., 1993; van der Kooy, Mucha, O'Shaughnessy, \& Bucenieks, 1982), this finding lends credence to an explanation of the deleterious effect of UCS preexposure as possibly being due to context-specific tolerance to the reinforcing effects of morphine.

\section{REFERENCES}

Bardo, M. T., Miller, J. S., \& Neisewander, J. L. (1984). Conditioned place preference with morphine: The effect of extinction training on the reinforcing CR. Pharmacology, Biochemistry \& Behavior, 21, 545-549.

Cappell, H., \& LeBlanc, A. E. (1977). Parametric investigations of the effects of prior exposure to amphetamine and morphine on conditioned gustatory aversion. Psychopharmacology, 51, 265-271.

Gaiard, M., Bartolett, H., Bacchi, A., Gubellin, C., Costa, M. \& BABBiNi, M. (1991). Role of repeated exposure to morphine in determining its affective properties: Place and taste conditioning in rats. Psychopharmacology, 103, 183-186.

Hinson, R. E. (1982). Effects of UCS preexposure on excitatory and inhibitory rabbit eyelid conditioning: An associative effect of conditioned contextual stimuli. Journal of Experimental Psychology: Animal Behavior Processes, 8, 49-61.
Hinson, R. E., McKee, S. A., Lovenjak, T., \& WALl, A.-M. (1993). The effect of the CS-UCS interval and extinction on place conditioning and analgesic tolerance with morphine. Journal of Psychopharmacology, 7, 164-172.

Kamin, L. J. (1961). Apparent adaptation effects in the acquisition of a conditioned emotional response. Canadian Journal of Psychology, $15,176-188$

LETT, B. T. (1989). Repeated exposures intensify rather than diminish the rewarding effects of amphetamine, morphine and cocaine. Psychopharmacology, 98, 357-362.

Martin, G. M., Bechara, A., \& Van der Kooy, D. (1988). Morphine preexposure attenuates the aversive properties of opiates without preexposure to the aversive properties. Pharmacology, Biochemistry \& Behavior, 30, 687-692.

MUCHA, R. F. \& IVERSON, S. D. (1984). Reinforcing properties of morphine and naloxone revealed by conditioned place preferences: A procedural examination. Psychopharmacology, 82, 241-247.

RANDICH, A., \& LoLoRDO, V. M. (1979a). Associative and nonassociative theories of the UCS preexposure phenomenon: Implications for Pavlovian conditioning. Psychological Bulletin, 86, 523-548.

RANDich, A., \& LoLoRDo, V. M. (1979b). Preconditioning exposure to the unconditioned stimulus affects the acquisition of a conditioned emotional response. Learning \& Motivation, 10, 245-277.

SColes, M. T., \& Siegel, S. (1986). A potential role of saline trials in morphine-induced place-preference conditioning. Pharmacology, Biochemistry \& Behavior, 25, 1160-1173.

Sherman, J. E., Pickman, C., Rice, A., Liebeskind, J., \& HolMAN, E. (1980). Rewarding and aversive effects of morphine: Temporal and pharmacological properties. Pharmacology, Biochemistry \& Behavior, 13, 501-505.

Shippenterg, T. S., Emmett-Oglesby, M. W., Ayesta, F. J., \& Hertz, A. (1988). Tolerance and selective cross-tolerance to the motivational effects of opioids. Psychopharmacology, 96, 110-115.

SIEGEL, S. (1983). Classical conditioning, drug tolerance and drug dependence. In Y. Israel, F. B. Glaser, H. Kalant, R. E. Popham, W. Schmidt, \& R. E. Smart (Eds.), Research advances in alcohol and drug problems (Vol. 7, pp. 207-246). New York: Plenum.

VAN Der KoOY, D., Mucha, R., O'Shaughnessy, M., \& BuCENIEKS, P. (1982). Reinforcing effects of brain microinjections of morphine revealed by conditioned place preference. Brain Research, 243, 107-117.

Wall, A.-M., Hinson, R. E., Schmidt, E., Johnston, C., \& STREATHER, A. (1990). Place conditioning with d-amphetamine: The effect of the CS-UCS interval and evidence of a place avoidance. Animal Learning \& Behavior, 18, 393-400.

(Manuscript received April 1, 1993; revision accepted for publication October 27, 1993.) 